\title{
SINERGIA
}

REVISTA DO INSTITUTO DE CIÊNCIAS ECONÔMICAS, ADMINISTRATIVAS E CONTÁBEIS (ICEAC)

\section{EFEITO DA ESTRUTURA DE CAPITAL SOBRE DIFERENTES PERFIS DE RENTABILIDADE DAS EMPRESAS LISTADAS NA B3}

\author{
MARCOS ANDREZ SANTOS DA SILVA \\ GABRIELA FERREIRA SANTOS* \\ ANTONIO GUALBERTO PEREIRA** \\ JORGE DE SOUZA BISPO***
}

\section{RESUMO}

O objetivo deste estudo é investigar as relações entre a estrutura de capital e a rentabilidade das empresas listadas na B3 nos anos de 2011 a 2019. A partir de 1.940 observações, foram estimados três modelos econométricos por meio de regressões quantílicas e dados agrupados (POLS). Os resultados evidenciaram que o endividamento de curto prazo afeta positivamente a rentabilidade das empresas, com destaque para aquelas situadas no $1^{\circ}$ quantil (menor rentabilidade) e $9^{\circ}$ quantil (maior rentabilidade). Não foi identificado efeito estatisticamente significante dos endividamentos de longo prazo e total sobre a rentabilidade das empresas. Esses resultados contrariam a teoria da irrelevância da fonte de financiamento proposta por Modigliani e Miller (1958), entretanto não é possível concluir que contrariam a proposição da teoria de Pecking Order, pois não se examinou a existência de benefícios fiscais associados às escolhas de endividamento das empresas que compuseram a amostra. Ainda que inconclusiva para os efeitos do endividamento de longo prazo e total, esta pesquisa avança em relação aos estudos anteriores sobre esta temática ao aplicar um método de estimação ainda pouco explorado na literatura em Contabilidade e Finanças, o qual se mostrou aderente às características dos dados.

Palavras-Chave: Estrutura de capital; Rentabilidade; Quantil; Teoria Pecking Order, Teoria do Tradeoff.

\section{ABSTRACT}

The aim of this study is to investigate the relationship between the capital structure and profitability of companies listed on B3 in the years 2011 to 2019. From 1,940 observations, three econometric models were estimated using quantile regressions and a regression with Pooled Ordinary Least Squares (POLS). The results showed that short-term debt positively affects the profitability of companies, with an emphasis on those located in the 1st quantile (lowest profitability) and 9th quantile (highest profitability). There was no statistically significant effect of long-term and total debt on corporate profitability. These results contradict the theory of irrelevance of the funding source proposed by Modigliani and Miller (1958), however, it is not possible to conclude that they contradict the proposition of the Pecking Order theory, because the existence of tax benefits associated with the choices of indebtedness of the companies that composed the sample. Although inconclusive for the effects of long-term and total debt, this research advances in relation to previous studies on this theme by applying a method of estimation that has not been enough explored in the literature in accounting and finance and that has shown itself to be adherent to the data characteristics.

Keywords: Capital structure; Profitability; Quantil; Pecking Order Theory; Tradeoff theory.

Recebido em: 10-03-2021 Aceito em: 12-07-2021

\section{INTRODUÇÃO}

A estrutura de capital diz respeito à composição acionária da empresa ou, mais especificamente, à participação relativa das várias fontes de financiamento na composição do total de obrigações (MESQUITA e LARA, 2004). A análise é feita considerando o volume de ações ordinárias e preferenciais e qual a porcentagem da participação de capital de terceiros que a empresa possui.

Ao analisar a estrutura de capital, pode-se obter o grau de alavancagem financeira e os custos das operações, permitindo que a taxa de retorno possa ser influenciada por essa composição. Nesse sentido, a decisão sobre qual estrutura de capital adotar é de suma importância devido à necessidade de maximizar

\footnotetext{
* Mestrando em Ciências Contábeis pelo Programa de Pós-Graduação em Contabilidade da Universidade Federal da Bahia (UFBA).

".."Mestre em Ciências Contábeis pelo Programa de Pós-Graduação em Contabilidade da Universidade Federal da Bahia (UFBA).

*** Doutor em Controladoria e Contabilidade - Faculdade de Economia, Administração e Contabilidade - FEA/USP. Docente do Programa de Pós-Graduação em Contabilidade - Universidade Federal da Bahia (UFBA). E-mail: antoniopereira@ufba.br

Doutor em Controladoria e Contabilidade - Faculdade de Economia, Administração e Contabilidade - FEA/USP. Docente do Programa de Pós-Graduação em Contabilidade da Universidade Federal da Bahia (UFBA).
} 
seus retornos e, assim, ter a habilidade de sobreviver em ambientes competitivos (MESQUITA e LARA, 2004; ABOR 2005; GIL, BIGER e MATHUR, 2011).

Nessa perspectiva, algumas empresas tendem a recorrer a opções de financiamento que facilitem a obtenção dele, como empréstimos bancários, nos quais a rapidez da transação é compensada pelas altas taxas de juros que acabam por elevar o custo dos recursos captados. Esse capital mais oneroso tende a reduzir a rentabilidade da empresa e, muitas vezes, a afastar investidores.

Conforme Morante e Timaco (2009), os recursos obtidos por endividamento são direcionados, prioritariamente, para o financiamento de projetos que expandam o nível das operações da organização, portanto podem gerar valor no longo prazo. Se obtiverem um bom retorno, podem gerar futuros fluxos de caixa para a empresa e seus acionistas.

Considerando a inexistência de urgência para a captação desses recursos, as empresas possuem a oportunidade de planejar-se para o endividamento, de forma que esta transação proporcione maiores benefícios econômicos e eleve a qualidade da estrutura de capital da organização. Uma das vantagens do financiamento planejado é que este pode ser obtido mediante fontes de financiamento menos onerosas, como a emissão de títulos de dívida ou empréstimos em banco de desenvolvimento.

Portanto, um há uma ampla gama de fontes de financiamento para que as empresas optem de que forma se financiar, alavancando seus resultados de curto e longo prazos. Para uma melhor compreensão deste fenômeno, faz-se necessário verificar como as empresas estão se financiando e como o seu capital está estruturado.

O tema possui diversos estudos seminais, Modigliani e Miller (1958 e 1963), os quais defenderam, inicialmente, que estrutura de capital de uma empresa não seria relevante (MODIGLIANI e MILLER, 1958) e, em seguida, indicaram que as vantagens fiscais do financiamento da dívida são um pouco maiores do que foi sugerido originalmente (MODIGLIANI e MILLER, 1963). Jensen e Meckling (1976), em oposição, afirmam que o endividamento de uma empresa leva a custos de agência e o estudo de Myers (1984) desenvolve a teoria do Pecking Order.

Pesquisas já realizadas, no Brasil, mostram resultados que divergem no sentido da relação entre o endividamento e a rentabilidade da empresa, embora apontem que a Teoria do Pecking Order é mais consistente do que a Teoria do Trade-Off. Nesse sentido, esta pesquisa se justifica pela discussão e busca de entendimento sobre os impactos da estrutura de capital nas empresas brasileiras.

Dessa forma, as contribuições teóricas deste estudo se dão a partir da ampliação do conhecimento na área, pois apresenta evidências no Brasil do efeito do endividamento de curto prazo, longo prazo e total sobre a rentabilidade das empresas listadas na B3. O conhecimento teórico se expande para a prática, visto que as organizações podem adotar a melhor estrutura de endividamento que the ofereça maior rentabilidade. Adicionalmente, pode-se destacar que os achados geram impactos sobre os gestores e suas organizações e para os pesquisadores da área de negócios nos seguintes sentidos: (i) auxiliam gerentes financeiros e gestores a conhecer as vantagens e dificuldades ensejadas por diferentes fontes de financiamento e os permite identificar opções para a melhoria da estrutura de capitais; (ii) contribuem para futuros estudos sobre a temática em tela, aumentando o acervo numa área pouco explorada em pesquisas nacionais.

Diferentemente da maioria dos trabalhos anteriores que analisaram a relação entre estrutura de capital e rentabilidade, a partir de estimações por mínimos quadrados ordinários, a presente pesquisa confrontou a estimação com dados agrupados com a regressão quantílica para o primeiro quantil (empresas de menor rentabilidade), o quantil mediano e o nono quantil (empresas de maior rentabilidade). Tal abordagem busca oferecer evidências adicionais sobre o objeto de estudo, assumindo que os dados contábeis, no Brasil, estão sujeitos a uma alta heterogeneidade (DUARTE, GIRÃO e PAULO, 2017) e que a regressão quantílica é mais robusta a dados com tais características.

Este trabalho buscou trazer contribuições para a literatura que relaciona a estrutura de capital e a rentabilidade das empresas. Para isso, foi elaborada a seguinte questão de pesquisa: Quais os efeitos da estrutura de capital das empresas de capital aberto listadas na B3 sobre suas respectivas rentabilidades?

Replicando as pesquisas realizadas por Abor (2005) e Gil, Biger e Mathur (2011), o objetivo geral deste artigo é entender a relação entre estrutura de capital e rentabilidade nas empresas de capital aberto listadas na B3, considerando diferentes extratos de rentabilidade.

A proposta de replicação de tais trabalhos, no contexto nacional, se justifica pelo lapso temporal estudado (relativamente mais recente) e pelas características do mercado brasileiro (alta concentração acionária, redução recente na taxa básica de juros, oligopólio no setor bancário, entre outras), que conferem ao presente trabalho uma possibilidade de interpretação diferente da realizada pelos supracitados autores.

Como meios de alcançar o objetivo geral, foram selecionadas, a partir da literatura sobre o tema, as variáveis que influenciam na rentabilidade das empresas e foram estimados modelos econométricos através da regressão quantílica e dados agrupados (POLS) para analisar o efeito do endividamento de curto prazo, de longo prazo e endividamento total no retorno sobre o patrimônio líquido (ROE).

Além desta introdução, o artigo apresenta, na seção 2, o referencial teórico, que trata dos conceitos 
sobre estrutura de capital, rentabilidade e a relação entre essas variáveis. Em seguida, é apresentada a metodologia utilizada na construção e no desenvolvimento do trabalho. $\mathrm{Na}$ análise e discussão dos resultados, são evidenciados os resultados dos testes de hipóteses e, por fim, apresentadas as considerações finais.

\section{REFERENCIAL TEÓRICO}

Nesta seção, são apresentados os conceitos e a literatura sobre estrutura de capital, rentabilidade e de que forma essas variáveis se relacionam, servindo de sustentação teórica para o presente trabalho.

\subsection{Estrutura de capital}

A decisão sobre a estrutura de capital a adotar é crucial para a organização da empresa devido à necessidade de maximizar seus retornos e ter a habilidade de sobreviver em ambientes competitivos (ABOR, 2005; GIL, BIGER e MATHUR, 2011).

Segundo Camilo et al (2010), essa decisão pode formar um recurso organizacional que é raro, valioso e de difícil imitação e substituição, e importante para a vantagem competitiva em um ambiente como o do Brasil.

Segundo Abor (2005), diversas teorias têm avançado na tentativa de explicar a estrutura de capital das firmas. Desde os trabalhos seminais de Modigliani e Miller (1958 e 1963) até as pesquisas atuais, duas teorias têm sido frequentemente discutidas, a teoria do Pecking Order, debatida por Myers (1984) e Myers e Majluf (1984), e a teoria do Trade-Off (FAMA e FRENCH, 2002; DAVID, NAKAMURA e BASTOS 2009; SANTOS et al, 2018; SILVA, STEINKE e ZANCHET 2018), discutida por Jensen e Meckling (1976).

Estudos nessa área parecem concordar que os trabalhos de Modigliani e Miller $(1958,1963)$ proporcionaram um impulso substancial no desenvolvimento do quadro teórico da estrutura de capital (ABOR, 2005; SILVA, STEINKE e ZANCHET, 2018). Nesses estudos, os autores postulavam que a estrutura de capital das empresas não afetaria o seu valor (DAVID, NAKAMURA e BASTOS, 2009), sendo preconizado que a estrutura de capital é irrelevante para a empresa (SANTOS et al, 2018). Porém, diversas pesquisas defendem que existe uma estrutura de capital ótima mesmo que o meio acadêmico ainda não tenha encontrado tal modelo (ABOR, 2005; GIL, BIGER e MATHUR, 2011).

A teoria do Trade-Off (Static Tradeoff Thory - STT) foi desenvolvida por Myers (1984) e estabelece que é possível uma estrutura ótima de capital que visa, de um lado, maximizar o resultado dos acionistas e, de outro, reduzir os custos de endividamento. Nesse sentido, o equilíbrio ótimo entre recursos próprios e recursos de terceiros requereria do gestor uma análise dos benefícios fiscais derivados da dívida assumida em contrapartida aos custos incorridos em situação de falência (DAVID, NAKAMURA e BASTOS, 2009).

Haussman et al (2018) observam que, nessa teoria, ocorrem custos e benefícios em relação ao endividamento e que as empresas escolhem sua alavancagem a partir do equilíbrio entre os custos e os benefícios adicionais envolvidos com a dívida.

A estrutura ótima de capital prevista na teoria do Trade-Off varia de empresa para empresa, conforme descrito por Bittencourt e Albuquerque (2018). Assim, empresas com ativos tangíveis e mais lucrativas, por exemplo, por possuírem maior propensão a obter benefícios fiscais, tendem a elevar o volume de endividamento. Já empresas pouco rentáveis tendem a utilizar recursos próprios e, consequentemente, serem menos endividadas.

Por outro lado, os estudos de Myers (1984) e Myers e Majluf (1984) desenvolvem uma teoria alternativa conhecida como o modelo de decisões financeiras, Pecking Order (FAMA e FRENCH, 2002). O pressuposto assumido pelos autores, ao desenvolverem a teoria, é que o mercado é assimétrico e essa assimetria afeta a escolha entre financiamento interno (lucros retidos) e externo (financiamentos e emissão de ações), estabelecendo uma hierarquia de fontes de financiamento (BITTENCOURT e ALBUQUERQUE, 2018).

Segundo Haussman et al (2018), a teoria do Pecking Order estabelece que, a partir do momento em que a organização tem ativos, oportunidades de crescer e ainda busca pela estrutura de capital para mudar, ela deveria concentrar suas dívidas como uma maneira de financiar ativos e ações.

Nessa teoria, as empresas optam por recursos de forma hierárquica, selecionando, inicialmente, as fontes internas, posteriormente, as externas de maior facilidade e menor custo e, ao final, as externas de maior dificuldade e maior custo (DAVID, NAKAMURA e BASTOS, 2009). A hierarquia entre as fontes externas de financiamento orienta pelo uso inicial de endividamento (empréstimos e financiamentos), seguido da emissão de título híbridos e, por último, a emissão de novas ações.

Acerca da Teoria de Pecking Order, Myers (1984) afirma que o financiamento, por meio da emissão de ações, é mais custoso para a empresa em virtude de existir uma assimetria informacional entre gestores e o mercado. Nesse sentido, há um indicativo de que a empresa buscará recursos através de ações se não for capaz de suprir suas atividades com recursos próprios. Logo, a predileção por recursos internos está justificada (salvo situações de benefícios tributários ou incentivos governamentais). 
Autores como Fama e French (2002), Abor (2005) e Gil, Biger e Mathur (2011) concordam que a estrutura de capital de uma empresa é afetada por custos de falência e custos de agência. Os custos de falência são os custos diretamente incorridos quando é percebido que a probabilidade de a firma incorrer em falhas contratuais é diferente de zero. (GIL, BIGER e MATHUR, 2011). Segundo Abor (2005), a probabilidade de falência aumenta com o nível de dívidas, pois cresce o medo de que a empresa não seja capaz de gerar lucros para pagar os dividendos e os empréstimos ao mesmo tempo.

Os custos de agência são discutidos por Jensen e Meckling (1976), que afirmam que o endividamento também leva a esses custos. Esses autores afirmam que um dos incentivos associados às dívidas é o gerente engajar-se em atividades de altos retornos, mesmo que a probabilidade de sucesso seja muito baixa, pois será ele que se beneficiará e, em um caso de insucesso, os credores arcarão com a maioria dos custos. Ressalta-se que, para o propósito deste trabalho, não serão discutidos os custos de agência.

Brealey, Myers e Allen (2011) esclarecem que a hierarquia prevista pela Teoria Pecking Order explica a existência de um maior endividamento para empresas menos lucrativas, as quais recorrem a recursos de terceiros por não disporem de excedentes de caixa para financiar seus investimentos.

Ancorando seus estudos nas teorias de Tradeoff e Pecking Order, Rajan e Zingales (1995) identificaram que as variáveis tamanho, tangibilidade, rentabilidade e oportunidade de investimento como correlacionadas com estrutura de capital das empresas, tanto nos Estados Unidos quanto nos outros países do G7. Paralelamente, esses autores sugerem que fatores institucionais dos países podem modular os efeitos destas variáveis sobre a estrutura de capital das empresas.

As pesquisas, no Brasil, sobre estrutura de capital têm apontado uma maior aderência à teoria Pecking Order (BASTOS e NAKAMURA, 2009; MEDEIROS e DAHER, 2008; PEROBELLI e FAMÁ, 2003; ALBANEZ e VALLE, 2009; CORREA, BASSO e NAKAMURA, 2013)) embora outros trabalhos (NAKAMURA et al., 2007; MARTINS e TERRA, 2014) tenham encontrado resultados que suportam tanto a teoria Pecking Order quanto a teoria de Trade-Off.

\subsection{Rentabilidade}

A rentabilidade é uma das perspectivas das medidas do desempenho corporativo, expressando a capacidade que uma companhia tem de gerar lucros através da utilização de seus ativos (GOTARDELO, 2006). Os indicadores de rentabilidade geralmente utilizados em pesquisas são o ROA (return on total assets), que indica a taxa de retorno sobre o ativo total, e o ROE (return on equity), que indica a taxa de retorno sobre o patrimônio (AHMAD, 2013).

Nesta pesquisa, foi utilizado como variável dependente do modelo o ROE, da mesma forma que os estudos de Abor (2005) e de Gill, Biger e Mathur (2011). Em relação a esse indicador, Catapan e Colauto (2014) afirmam que o seu comportamento é função da rentabilidade das vendas (margem líquida) e do giro do patrimônio. Uma das vantagens da utilização do ROE é que ele pode ser comparado a outros rendimentos no mercado. Dessa forma, é possível verificar se a rentabilidade da empresa é superior ou inferior a outras alternativas.

Fu, Ke e Huang (2002) discutem a relação entre rentabilidade e a estrutura de financiamento em pequenas empresas no Taiwan. Os resultados da pesquisa indicam uma relação significativamente positiva entre rentabilidade e financiamento através de capital próprio, porém uma relação significativamente negativa entre lucratividade e dívida por capital de terceiros. Além disso, os autores sugerem que a lucratividade das pequenas empresas está possivelmente relacionada às condições econômicas externas e à lucratividade anterior das empresas. Segundo Fu, Ke e Huang (2002), ao investir em um ativo, uma pequena empresa deve determinar qual é a fonte apropriada de financiamento, verificando a combinação adequada de dívida e de capital próprio.

Essa mesma ideia é seguida por Pinho (2013). Segundo a autora, deve existir uma estrutura de capital ótima capaz de maximizar o lucro da empresa. Essa relação tem sido investigada, entretanto as teorias existentes são contraditórias entre si. A teoria do Pecking Order (MYERS, 1984; MYERS e MAJLUF, 1984) apresenta relação negativa entre a alavancagem e a rentabilidade, enquanto a teoria do Trade-Off (JENSEN e MECKLING, 1976) prevê uma relação positiva.

\subsection{Estrutura de capital e rentabilidade}

A relação entre a estrutura de capital e a rentabilidade já foi evidenciada por alguns autores a partir de testes empíricos em diferentes países. Gil, Biger e Mathur (2011) afirmam que essa relação não deve ser ignorada, visto que tal relação pode garantir a sobrevivência da empresa no longo prazo.

Wald (1999) realizou um teste empírico no qual analisou os fatores específicos das empresas que estavam correlacionados com sua estrutura de capital em países como França, Alemanha, Japão, Reino Unido e Estados Unidos. Os resultados foram parecidos em relação à média de endividamento entre as 
empresas de diferentes países. Foram encontradas diferenças entre o endividamento de longo prazo e a rentabilidade, tamanho e crescimento das empresas, além de encontrar evidências de que existem associações entre as diferenças na estrutura de capital das empresas e as diferenças institucionais dos países estudados.

Em seu estudo, Abor (2005) investigou a relação entre a estrutura de capital e a rentabilidade das firmas listadas no Ghana Stock Exchange (GSE) no período de 1998 a 2002, por meio de análise de regressão, estimando funções que relacionavam o retorno sobre patrimônio líquido (ROE) com medidas de estrutura de capital. Seus resultados revelaram uma relação positiva e significante entre a variável utilizada para operacionalizar o endividamento de curto prazo e o ROE. Resultados diferentes da relação entre o endividamento de longo prazo e o $\mathrm{ROE}$, que trouxeram uma relação negativa. E, em relação ao endividamento total e o ROE, foram encontrados resultados significantes e negativos.

Gil, Biger e Mathur (2011), em busca de estender a pesquisa de Abor (2005), analisaram a relação entre estrutura de capital e rentabilidade ao examinar empresas americanas de serviço e manufatureiras pertencentes ao New York Stock Exchange (NYSE), no período de 2005 a 2007, com uma amostra de 272 empresas. A análise, por meio de regressão, demonstrou relação positiva entre o ROE e todas as três variáveis que representavam endividamento, de curto prazo, longo prazo e endividamento total.

\subsection{Estudos anteriores e formulação de hipóteses}

A fim de formular as hipóteses desta pesquisa, estudos anteriores sobre o endividamento e rentabilidade foram revisitados, buscando expor quais foram os objetivos dos autores, a amostra e os resultados encontrados.

Em seus estudos, Simerly e Li (2000) testaram se a estrutura de capital de uma empresa é influenciada pelo dinamismo ambiental. As variáveis utilizadas foram o endividamento, o ROA médio e o ROI médio, com uma amostra de 700 grandes empresas dos EUA. Os resultados indicaram que o impacto da alavancagem financeira (positivo ou negativo) depende de o ambiente de negócios ser estável ou dinâmico.

O objetivo de Mesquita e Lara (2004) foi verificar a relação entre as taxas de retorno das empresas brasileiras com a composição do capital. Utilizaram, para isso, as variáveis endividamento de curto prazo, endividamento de longo prazo, participação do capital próprio e ROE. Os testes utilizando regressão linear múltipla com 70 empresas do Brasil nos setores industrial e de serviço apontaram que as dívidas, de longo prazo, afetam negativamente (embora não significativamente) o ROE, e as dívidas de curto prazo afetam positivamente e, de forma significativa, o ROE.

Abor (2005) investigou a relação entre a estrutura de capital e a lucratividade das empresas listadas na Bolsa de Valores de Gana (GSE) durante um período de cinco anos. A análise contemplou uma amostra de 22 empresas listadas em Gana (de 1998 a 2002), utilizando as variáveis endividamento de curto e de longo prazos, participação do capital próprio e ROE. Os resultados indicaram que a dívida de curto prazo e o endividamento total influenciam positivamente e significativamente o ROE.

Gill, Bigger e Mathur (2011) examinam a relação entre a estrutura de capital e a lucratividade das empresas americanas de serviços e manufatura. A seleção de variáveis, quais sejam endividamento de curto e de longo prazos, participação do capital próprio e ROE, é baseada na estrutura alternativa de capital, teorias de lucratividade e trabalhos empíricos anteriores. Os resultados sugerem que as empresas lucrativas dependem mais da dívida como sua principal opção de financiamento. Isso ocorre porque os juros da dívida são dedutíveis nos impostos nos Estados Unidos.

Habib, Khan e Wazir (2016) realizaram um estudo com o objetivo de ampliar o conhecimento empírico existente sobre o impacto da dívida na rentabilidade das empresas. Utilizando as variáveis endividamento de curto e longo prazos, endividamento total e ROA com uma amostra de 340 empresas listadas (2003-2012), os resultados dos autores indicaram uma relação significativa, negativa, entre dívida de curto prazo, dívida de longo prazo, dívida total e ROA.

Leite e Silva (2019) visaram analisar a relação da estrutura de capital e do valor econômico agregado no desempenho econômico em empresas industriais brasileiras e chilenas. A composição da amostra foi de 127 empresas, sendo 82 empresas brasileiras e 45 chilenas. Os resultados evidenciaram que, quanto maior a participação de capital de terceiros na estrutura de capital das empresas, menor o desempenho econômico das organizações analisadas. $O$ valor econômico agregado apresentou baixa relação negativa com o desempenho econômico das empresas brasileiras e baixa relação positiva com o desempenho econômico das empresas chilenas.

Os estudos de Dias et al (2020) tiveram como objetivo analisar a influência da utilização das práticas de governança corporativa e da estrutura de capital sobre o desempenho e o risco de firmas de capital aberto. A amostra contemplou as empresas brasileiras listadas na B3 e com ações negociadas, atuantes na indústria manufatureira, abrangendo os anos de 2009 a 2015. As variáveis dependentes foram o Q de Tobin e a Volatilidade do Retorno das Ações; já as independentes foram o endividamento total, os endividamentos de curto e longo prazo e a governança corporativa. 
Os resultados de Dias et al (2020) sugerem que o incremento na adoção de boas práticas de governança apresentará efeitos positivos no desempenho, caso os níveis de endividamento sejam mantidos em níveis mínimos, implicando maior utilização de capital próprio.

Os estudos de Pamplona e Silva (2020) verificaram a influência da estrutura de capital no desempenho econômico de empresas industriais brasileiras sob a ótica não linear. As variáveis utilizadas para o desempenho foram o ROA e ROE. A amostra englobou 232 organizações listadas na B3, com dados de 1996 a 2017. Os resultados enquadram-se na teoria do Trade-off e apontam que o nível ideal de endividamento para maximizar o ROE é de $35,78 \%$, enquanto, para impulsionar o ROA, é de $45,81 \%$.

Considerando os estudos prévios e a importância que a estrutura de capital e a rentabilidade representam para a empresa, para atender ao objetivo deste trabalho, foram investigadas as seguintes hipóteses:

Hipótese 1: O endividamento de curto prazo influencia negativamente a rentabilidade das empresas listadas na B3.

Hipótese 2: O endividamento de longo prazo influencia negativamente a rentabilidade das empresas listadas na B3. B3.

Hipótese 3: O endividamento total influencia negativamente a rentabilidade das empresas listadas na

$\mathrm{Na}$ metodologia, apresentada na sequência, são apesentados e discutidos os meios utilizados para operacionalizar as variáveis frequentemente citadas pela literatura sobre o tema, bem como as regressões testadas.

\section{METODOLOGIA}

Nesta seção, é apresentada a metodologia utilizada para a realização da pesquisa. Inicialmente, definese a amostra e, em seguida, é descrita a operacionalização das variáveis operacionais e apresentado o modelo econométrico.

\subsection{Definição da amostra}

Os dados foram coletados no Economática, que fornece tanto dados contábeis quanto dados de mercado, caracterizados como secundários. Os softwares utilizados para tratamento de dados foram o Excel ${ }^{\circledR}$ e o $R^{\circledR}$. Os testes econométricos foram realizados no Stata ${ }^{\circledR} 13.0$.

A construção da amostra, objeto deste estudo, está apresentada na tabela 01. Inicialmente, a partir das informações de 276 empresas não financeiras ativas na B3, na série temporal de 2011 a 2019, a amostra continha 2.043 observações. Após a exclusão de 97 observações devido à falta de informações em diversas variáveis e 6 observações que se referiam a empresas em recuperação judicial, a amostra final ficou definida com 1.940 observações. Como a distribuição da quantidade de empresas é não linear, obteve-se um mínimo de 202 empresas em 2018 e um máximo de 270 empresas em 2019.

Tabela 1 - Amostra analisada

\begin{tabular}{l|r}
\hline \multicolumn{1}{c|}{ Item } & Número de Observações \\
\hline Amostra Inicial & 2.043 \\
\hline ( - ) Dados ausentes nas variáveis & -97 \\
\hline (-) Dados de empresas em recuperação & -6 \\
judicial & 1.940 \\
\hline ( =) Amostra Final &
\end{tabular}

Fonte: elaborado pelos autores

É válido destacar que a delimitação temporal da coleta de dados (2011 a 2019) se deveu a dois parâmetros: (i) maior série temporal possível em um período posterior ao do artigo base "Gil, Biger e Mathur (2011)" e; (ii) abranger um período posterior à adoção integral das normas internacionais de contabilidade, que teve a adoção do full IFRS em 2010.

\subsection{Definição operacional das variáveis}

\subsubsection{Variável dependente}

Em consonância com os estudos de Abor (2005) e de Gill, Biger e Mathur (2011), a variável dependente deste estudo é o Retorno sobre o Patrimônio Líquido (ROE). Seu cálculo é feito através da divisão do Lucro 
Antes dos Juros e do Imposto de Renda (LAJIR) pelo Patrimônio Líquido (PL), a partir das informações de 2011 a 2019 de cada empresa. A escolha do LAJIR, para o cálculo do ROE, justifica-se pela capacidade de demonstrar a geração real de caixa da empresa, sem interferências de resultados não operacionais.

O quadro 03 apresenta informações sobre a variável dependente, o ROE, sua fórmula de cálculo, bem como os autores que utilizaram essa variável em seus modelos.

Quadro 3 - Variável Dependente

\begin{tabular}{|c|c|c|c|}
\hline Sigla & Nome & Fórmula & Autores \\
\hline ROE & $\begin{array}{c}\text { Retorno sobre Patrimônio } \\
\text { Líquido }\end{array}$ & LAJIR/PL & Abor (2005); Gill et al (2011); Gorla, Hein e Silva \\
(2018).
\end{tabular}

Fonte: elaborado pelos autores

\subsubsection{Variáveis independentes}

Neste estudo, foram estimados três modelos econométricos, nos quais são alteradas as variáveis independentes para representar três diferentes formas de endividamento.

As variáveis independentes do modelo, os conceitos considerados para este trabalho e de acordo com a literatura pesquisada, são definidos como: (i) Endividamento de Curto Prazo (ECP) - Obtido pela divisão entre as dívidas de curto prazo pelo ativo total; (ii) Endividamento de Longo Prazo (ELP) - Essa variável é caracterizada pela divisão entre as dívidas de longo prazo pelo ativo total; (iii) Endividamento Total (ET) Consiste na divisão entre as dívidas totais pelo ativo total.

No quadro 04, são apresentadas as variáveis independentes, suas fórmulas de cálculo e os autores que as adotaram em seus estudos.

Quadro 4 - Variáveis Independentes

\begin{tabular}{|c|c|c|c|}
\hline Sigla & Nome & Fórmula & Autores \\
\hline ECP & $\begin{array}{c}\text { Endividamento de } \\
\text { Curto Prazo }\end{array}$ & $\begin{array}{c}\text { Passivo Circulante / } \\
\text { Ativo Total }\end{array}$ & $\begin{array}{c}\text { Brito e Lima (2005); Abor (2005); Gill et al (2011); } \\
\text { Matias e Serrasqueiro (2017); Araujo et al (2017); } \\
\text { Gorla, Hein e Silva (2018) }\end{array}$ \\
\hline ELP & $\begin{array}{c}\text { Endividamento de } \\
\text { Longo Prazo }\end{array}$ & $\begin{array}{c}\text { Passivo não Circulante } \\
\text { / Ativo Total }\end{array}$ & $\begin{array}{c}\text { Brito e Lima (2005); Abor (2005); Gill et al (2011); } \\
\text { Matias e Serrasqueiro (2017); Araujo et al (2017) }\end{array}$ \\
\hline ET & $\begin{array}{c}\text { Endividamento } \\
\text { Total }\end{array}$ & $\begin{array}{c}\text { Passivo Total / Ativo } \\
\text { Total }\end{array}$ & $\begin{array}{c}\text { Brito e Lima (2005); Abor (2005); Gill et al (2011); } \\
\text { Matias e Serrasqueiro (2017); Araujo et al (2017); } \\
\text { Gorla, Hein e Silva (2018) }\end{array}$ \\
\hline
\end{tabular}

Fonte: elaborado pelos autores

Foram adotadas as seguintes variáveis de controle:

I. Tamanho (TAM) - Variável caracterizada pelo logaritmo natural do ativo total.

II. Tangibilidade (TANG) - Mensurada pela soma entre ativo imobilizado e estoque e posterior divisão desse resultado pelo ativo total.

III. Governança Corporativa (GC) - Para medir a influência da Governança Corporativa, variável dummy, na qual as empresas que estão, no Novo Mercado da B3, recebem valor 1, e empresas que não estão em nenhum dos níveis ou em algum dos outros níveis de GC recebem valor 0 .

IV. Market-to-book (MTB)-Calculada pela divisão entre o valor de mercado e o valor contábil dos ativos.

V. Índice de Liquidez Corrente (ILC) - Variável que representa o índice de liquidez da empresa, calculado pela divisão entre ativo circulante e passivo circulante.

O quadro 05 contém informações acerca das variáveis de controle e os autores que as adotaram em seus estudos. 
Quadro 5 - Variáveis de Controle

\begin{tabular}{|c|c|c|c|}
\hline Sigla & Nome & Fórmula & Autores \\
\hline TAM & Tamanho & $\begin{array}{c}\text { Logaritmo Natural do Ativo } \\
\text { Total }\end{array}$ & $\begin{array}{c}\text { Nakamura et. al. (2007); Brito et al. (2007); } \\
\text { Maia, Castro e Lamounier (2018); Silva et al } \\
\text { (2018); Lerner et al (2018) }\end{array}$ \\
\hline TANG & Tangibilidade & $\begin{array}{c}\text { (Ativo Imobilizado + } \\
\text { Estoques) / Ativo Total }\end{array}$ & $\begin{array}{c}\text { Bastos et al. (2009); Bastos e Nakamura } \\
\text { (2009); Santos et al (2018); Carvalho et al } \\
\text { (2018); Maia, Castro e Lamounier (2018) }\end{array}$ \\
\hline GC & $\begin{array}{c}\text { Governança } \\
\text { Corporativa }\end{array}$ & $\begin{array}{c}\text { Dum) para as empresas } \\
\text { listadas nos níveis 2 ou } \\
\text { Novo Mercado e 0 (zero), } \\
\text { caso contrário. }\end{array}$ & $\begin{array}{c}\text { Costa, Sampaio e Flores (2019); Nascimento et } \\
\text { al. (2018); Queiroz et al. (2017); Aguiar e } \\
\text { Pimentel (2017); Silva Junior e Martins (2017); } \\
\text { Souza, Peixoto e Santos (2016) }\end{array}$ \\
\hline MTB & $\begin{array}{c}\text { Market-to-Book } \\
\text { Valivos / Valor Contábil do } \\
\text { Ativos }\end{array}$ & $\begin{array}{c}\text { Bastos et al. (2009); Bastos e Nakamura } \\
\text { (2009); Kieschnick e Moussawi (2018) }\end{array}$ \\
\hline ILC & $\begin{array}{c}\text { İndice de Liquidez } \\
\text { Corrente }\end{array}$ & $\begin{array}{c}\text { Ativo Circulante / Passivo } \\
\text { Circulante }\end{array}$ & Bastos e Nakamura (2009) \\
\hline
\end{tabular}

Fonte: elaborado pelos autores

\subsection{Tratamento e testes econométricos}

Neste estudo, as regressões possuem a rentabilidade como variável dependente, operacionalizada pelo ROE da empresa, e as variáveis retiradas do teste de hipótese são o endividamento de curto prazo, de longo prazo e endividamento total. Por fim, as variáveis de controle da regressão são: tamanho da empresa, tangibilidade, nível de governança corporativa, market-to-book e o índice de liquidez corrente de cada organização.

Os modelos econométricos da pesquisa são apresentados conforme as seguintes equações:

$(\tau) \mathrm{ROE}_{\mathrm{i}, \mathrm{t}}=\beta_{0}(\tau)+\beta_{1}(\tau) \mathrm{ECP}_{\mathrm{i}, \mathrm{t}}+\beta_{2}(\tau) \mathrm{TAM}_{\mathrm{i}, \mathrm{t}}+\beta_{3}(\tau) \mathrm{TANG}_{\mathrm{i}, \mathrm{t}}+\beta_{4}(\tau) \mathrm{GC}_{\mathrm{i}, \mathrm{t}}+\beta_{5}(\tau) \mathrm{MTB}_{\mathrm{i}, \mathrm{t}}+\beta_{6}(\tau) \mathrm{ILC}_{\mathrm{it}}+\varepsilon_{\mathrm{i}, \mathrm{t}}$

$(\tau) \mathrm{ROE}_{\mathrm{i}, \mathrm{t}}=\beta_{0}(\tau)+\beta_{1}(\tau) \mathrm{ELP}_{\mathrm{i}, \mathrm{t}}+\beta_{2}(\tau) \mathrm{TAM}_{\mathrm{i}, \mathrm{t}}+\beta_{3}(\tau) \mathrm{TANG}_{\mathrm{i}, \mathrm{t}}+\beta_{4}(\tau) \mathrm{GC}_{\mathrm{i}, \mathrm{t}}+\beta_{5}(\tau) \mathrm{MTB}_{\mathrm{i}, \mathrm{t}}+\beta_{6}(\tau) \mathrm{ILC}_{\mathrm{it}}+\varepsilon_{\mathrm{i}, \mathrm{t}}$

$(\tau) \mathrm{ROE}_{\mathrm{i}, \mathrm{t}}=\beta_{0}(\tau)+\beta_{1}(\tau) \mathrm{ET}_{\mathrm{i}, \mathrm{t}}+\beta_{2}(\tau) \mathrm{TAM}_{\mathrm{i}, \mathrm{t}}+\beta_{3}(\tau) \mathrm{TANG}_{\mathrm{i}, \mathrm{t}}+\beta_{4}(\tau) \mathrm{GC}_{\mathrm{i}, \mathrm{t}}+\beta_{5}(\tau) \mathrm{MTB}_{\mathrm{i}, \mathrm{t}}+\beta_{6}(\tau) \mathrm{ILC}_{\mathrm{it}}+\varepsilon_{\mathrm{i}, \mathrm{t}}$

Onde:

( $\mathrm{T})$ = Parâmetro estimado para cada quantil;

$\beta_{0}=$ Intercepto;

$\beta_{1}, \beta_{2}, \beta_{3}, \beta_{4}, \beta_{5}, \beta_{6}=$ Coeficientes angulares associados às variáveis dependentes;

Conforme explicitado por Duarte, Girão e Paulo (2017), a escolha dos quantis a serem analisados pelo pesquisador é realizada de forma arbitrária, de modo que é factível verificar os outputs de tantos quantis quanto forem desejados. Foram considerados, no presente estudo, três quantis, conforme explicitado a seguir:

Q1 $(0,10):$ Quantil representado pelas empresas consideradas de menor rentabilidade.

Q2(0,50): Quantil representado pelas empresas consideradas de rentabilidade mediana

Q3 $(0,90)$ : Quantil representado pelas empresas consideradas de maior rentabilidade.

Para análise da relação entre a estrutura de capital de uma empresa e sua rentabilidade, foram efetuadas três regressões quantílicas: uma para endividamento de curto prazo, uma para endividamento de longo prazo e outra para endividamento total.

A estimação por regressão quantílica corresponde ao modelo introduzido por Koenker e Basset (1978), que possui propriedades análogas à estimação por Mínimos Quadrados Ordinários (KOENKER e BASSET, 1978), com foco de análise nos quantis da amostra.

Conforme apontado por Duarte, Girão e Paulo (2017), os dados em contabilidade e finanças, no Brasil, são bastante heterogêneos e sujeitos à presença de outliers. Identificou-se, na amostra da atual pesquisa, não apenas a ocorrência de outliers, mas também o não atendimento aos pressupostos para uma estimação por mínimos quadrados ordinários (MQO): o teste de Jarque-Bera rejeitou a hipótese nula de distribuição normal dos resíduos, e o teste de Breusch-Pagan rejeitou a hipótese de homocedasticidade dos resíduos. Tais elementos sugerem a escolha pela estimação quantílica, permitindo explorar os resultados entre os diferentes quantis. 
Koenker e Basset (1978) asseveram que a escolha da regressão quantílica é justificada pelas propriedades de robustez apresentadas pelo modelo, principalmente quanto a alguns dos pressupostos da estimação por Mínimos Quadrados Ordinários.

\section{ANÁLISE E DISCUSSÃO DOS RESULTADOS}

Esta seção apresenta a estatística descritiva das variáveis da pesquisa. Em seguida, para cada regressão utilizada, são apresentados: a matriz de correlação e os resultados da regressão, a partir dos quais são discutidas cada hipótese e seus achados.

\subsection{Estatísticas descritivas}

A tabela 02 apresenta as estatísticas descritivas da variável dependente (ROE) e para a variável endividamento de curto prazo (ECP), segregada em nove quantis, para as empresas que compuseram a amostra no lapso temporal de 2011 a 2019.

Tabela 2 - Estatísticas Descritivas - ROE e ECP

\begin{tabular}{|c|c|c|c|c|c|}
\hline Quantil & Variável & Mínimo & Máximo & Média & Desvio Padrão \\
\hline \multirow{2}{*}{10} & ROE & $-13,463$ & $-0,036$ & $-0,309$ & 1,282 \\
\hline & ECP & 0,002 & 0,084 & 0,057 & 0,022 \\
\hline \multirow{2}{*}{$2^{\circ}$} & ROE & $-0,035$ & 0,040 & 0,004 & 0,020 \\
\hline & ECP & 0,084 & 0,126 & 0,107 & 0,013 \\
\hline \multirow{2}{*}{$3^{\circ}$} & ROE & 0,040 & 0,091 & 0,067 & 0,015 \\
\hline & ECP & 0,127 & 0,169 & 0,148 & 0,013 \\
\hline \multirow{2}{*}{$4^{\circ}$} & ROE & 0,091 & 0,131 & 0,111 & 0,012 \\
\hline & ECP & 0,170 & 0,207 & 0,189 & 0,011 \\
\hline \multirow{2}{*}{$5^{\circ}$} & ROE & 0,131 & 0,169 & 0,150 & 0,011 \\
\hline & ECP & 0,207 & 0,247 & 0,228 & 0,011 \\
\hline \multirow{2}{*}{$6^{\circ}$} & ROE & 0,169 & 0,218 & 0,193 & 0,015 \\
\hline & ECP & 0,247 & 0,293 & 0,270 & 0,013 \\
\hline \multirow{2}{*}{$7^{0}$} & ROE & 0,218 & 0,284 & 0,249 & 0,019 \\
\hline & ECP & 0,293 & 0,342 & 0,316 & 0,014 \\
\hline \multirow{2}{*}{$8^{\circ}$} & ROE & 0,284 & 0,370 & 0,323 & 0,025 \\
\hline & ECP & 0,343 & 0,491 & 0,402 & 0,041 \\
\hline \multirow{2}{*}{$9^{\circ}$} & ROE & 0,370 & 4,185 & 0,520 & 0,368 \\
\hline & ECP & 0,495 & 4,272 & 1,084 & 0,721 \\
\hline \multirow{2}{*}{ Total } & ROE & $-13,463$ & 4,185 & 0,145 & 0,493 \\
\hline & ECP & 0,002 & 4,272 & 0,311 & 0,377 \\
\hline
\end{tabular}

Verifica-se, na tabela 2, que o endividamento, de curto prazo, varia de $0,2 \%$, percentual mínimo no primeiro quartil, até $427 \%$ no percentual máximo no nono quartil. Isso sugere que empresas mais rentáveis tendem a ser mais alavancadas com o uso de dívidas de curto prazo. Na mediana, o endividamento médio de curto prazo é de, aproximadamente, $32 \%$.

O nono quartil é o que apresenta o maior desvio padrão para o endividamento de curto prazo, sugerindo que uma rentabilidade maior está associada a níveis muito diversos de endividamentos de curto prazo (maior heterogeneidade). Uma das possíveis explicações é que foram selecionadas para amostra empresas de diversos segmentos, cujas necessidades e estratégias de endividamento de curto prazo podem variar bastante.

As estatísticas descritivas, para a variável endividamento de longo prazo, são apresentadas na tabela 03. Não serão repetidas as estatísticas descritivas para a variável dependente em razão de terem sido reportadas na tabela 02 . 
Tabela 3 - Estatísticas Descritivas - ELP

\begin{tabular}{c|c|c|c|c|c}
\hline Quantil & Variável & Mínimo & Máximo & Média & Desvio Padrão \\
\hline $1^{\circ}$ & ELP & 0,000 & 0,097 & 0,058 & 0,024 \\
\hline $2^{\circ}$ & ELP & 0,097 & 0,161 & 0,130 & 0,018 \\
\hline $3^{\circ}$ & ELP & 0,161 & 0,238 & 0,202 & 0,022 \\
\hline $4^{\circ}$ & ELP & 0,238 & 0,298 & 0,270 & 0,018 \\
\hline $5^{\circ}$ & ELP & 0,299 & 0,350 & 0,324 & 0,015 \\
\hline $6^{\circ}$ & ELP & 0,351 & 0,405 & 0,379 & 0,016 \\
\hline $7^{\circ}$ & ELP & 0,405 & 0,464 & 0,433 & 0,018 \\
\hline $8^{\circ}$ & ELP & 0,464 & 0,562 & 0,511 & 0,029 \\
\hline $9^{\circ}$ & ELP & 0,562 & 69,375 & 2,897 & 8,869 \\
\hline Total & ELP & 0,000 & 69,375 & 0,577 & 3,060 \\
\hline \multicolumn{5}{|c}{ Fonte: Elaborado pelos autores } \\
\hline
\end{tabular}

O endividamento de longo prazo, conforme descrito na tabela 3, varia de $0 \%$ até um máximo de $690 \%$, com indicação de empresas em situação de insolvência financeira em algum período do lapso temporal selecionado. Na mediana, o endividamento médio de longo prazo é de, aproximadamente, $32 \%$. Tal percentual é similar ao do endividamento de curto prazo, sugerindo que parte das empresas tenta equilibrar o endividamento de curto e de longo prazo.

No que se refere ao desvio padrão (indicador de heterogeneidade da amostra), percebe-se que o nono quartil apresenta um desvio padrão bem discrepante do restante da amostra. Conforme argumentado para o endividamento de curto prazo, ainda que de forma exploratória, isso pode estar associado à presença de outliers (dentro de setores e entre setores), ratificando um dos argumentos para o uso da regressão quantílica. As estatísticas descritivas, para a variável endividamento total, são apresentadas na Tabela 04.

Tabela 4 - Estatísticas Descritivas - ET

\begin{tabular}{c|c|c|c|c|c}
\hline Quantil & Variável & Mínimo & Máximo & Média & Desvio Padrão \\
\hline $1^{\circ}$ & ET & 0,040 & 0,298 & 0,195 & 0,068 \\
\hline $2^{\circ}$ & ET & 0,299 & 0,416 & 0,364 & 0,036 \\
\hline $3^{\circ}$ & ET & 0,416 & 0,488 & 0,454 & 0,021 \\
\hline $4^{\circ}$ & ET & 0,488 & 0,544 & 0,517 & 0,017 \\
\hline $5^{\circ}$ & ET & 0,544 & 0,602 & 0,571 & 0,016 \\
\hline $6^{\circ}$ & ET & 0,603 & 0,661 & 0,631 & 0,017 \\
\hline $7^{\circ}$ & ET & 0,662 & 0,731 & 0,696 & 0,020 \\
\hline $8^{\circ}$ & ET & 0,731 & 0,874 & 0,785 & 0,040 \\
\hline $9^{\circ}$ & ET & 0,875 & 70,368 & 3,792 & 9,097 \\
\hline Total & ET & 0,040 & 70,368 & 0,888 & 3,195 \\
\hline \multicolumn{5}{|c}{ Fonte: Elaborado pelos autores }
\end{tabular}

As estatísticas descritivas destacadas, na tabela 04, indicam um mínimo de 4\% e um máximo de 700\% de endividamento total para as empresas que compõem a amostra. Na mediana, observa-se um endividamento médio total de $57 \%$ (sendo este percentual equivalente ao observado no quarto quantil).

Destaca-se, nessa tabela, o desvio padrão, que é mais acentuado no primeiro quantil $(0,068)$ e no nono quantil $(9,097)$, sugerindo que podem existir outliers nos extremos da amostra. Uma forma de abordagem comum para uma estimação por mínimos quadrados ordinários seria a winsorização (GIRÃO, 2016), entretanto, na estimação por quantis, esta heterogeneidade não representa um elemento problemático a ser corrigido.

\subsection{Efeito do Endividamento de Curto Prazo sobre a Rentabilidade}

$\mathrm{Na}$ tabela 04 , estão os resultados da primeira regressão, estimada por meio de dados agrupados (POLS) e regressão quantílica. Aplicou-se a estimação com erros-padrão robustos à heterocedasticidade de White e foi realizado o teste de Fatores de Inflação de Variância (VIF), o qual deve seu maior valor igual a 
1,27 , atestando a ausência de multicolinearidade. O pressuposto de normalidade foi relaxado em função do tamanho da amostra e em respeito ao Teorema do Limite Central (MARÇAL et al., 2019).

A hipótese $\mathrm{H} 1$ prevê que o endividamento de curto prazo influencia negativamente a rentabilidade das empresas listadas na B3. O resultado permite refutá-la, pois o ECP é significante a 1\%, no 9o quantil, e a 10\%, no primeiro quantil. Adicionalmente, na estimação por dados agrupados, percebe-se a significância em nível de $10 \%$. Nesse sentido, o endividamento de curto prazo influencia, positivamente, a rentabilidade das empresas, sendo que este efeito é mais acentuado para as empresas de maior rentabilidade. Empresas com rentabilidade mediana não tem seu desempenho explicado pelo endividamento de curto prazo. Tais resultados convergem com pesquisas recentes que encontraram relação positiva entre a dívida de curto prazo e a rentabilidade das empresas (MESQUITA e LARA, 2004; ABOR, 2005; GILL, BIGGER e MATHUR, 2011).

Tabela 4 - Resultados por Dados Agrupado e por Quantil - ECP

\begin{tabular}{|c|c|c|c|c|}
\hline & pols & 1ㅇ Quantil & 5 Quantil & 9o Quantil \\
\hline & b/se & b/se & b/se & b/se \\
\hline \multirow{2}{*}{$\mathrm{ECP}$} & $0,0226+$ & $0,0332+$ & $-0,0042$ & $0,1379^{* *}$ \\
\hline & $(0,013)$ & $(0,019)$ & $(0,010)$ & $(0,020)$ \\
\hline \multirow{2}{*}{ TAM } & $0,0351^{* *}$ & $0,0324^{* *}$ & $0,0241^{* *}$ & $0,0187^{* *}$ \\
\hline & $(0,008)$ & $(0,004)$ & $(0,002)$ & $(0,004)$ \\
\hline \multirow{2}{*}{ TANG } & $-0,1059+$ & $-0,0338$ & $-0,0265+$ & $-0,0074$ \\
\hline & $(0,054)$ & $(0,028)$ & $(0,015)$ & $(0,029)$ \\
\hline \multirow{2}{*}{ GC } & $-0,0165$ & 0,0082 & 0,0016 & 0,0218 \\
\hline & $(0,028)$ & $(0,015)$ & $(0,008)$ & $(0,015)$ \\
\hline \multirow{2}{*}{ MTB } & $0,0577^{* *}$ & $0,0654^{* *}$ & $0,0515^{\star *}$ & $0,0166+$ \\
\hline & $(0,010)$ & $(0,008)$ & $(0,004)$ & $(0,009)$ \\
\hline \multirow{2}{*}{ ILC } & $-0,0025^{\star}$ & $-0,0032^{*}$ & $-0,0047^{\star *}$ & $-0,0015$ \\
\hline & $(0,001)$ & $(0,001)$ & $(0,001)$ & $(0,001)$ \\
\hline \multirow{2}{*}{ _cons } & $-0,6196^{\star *}$ & $-0,7681^{\star *}$ & $-0,3969^{\star *}$ & $-0,0993$ \\
\hline & $(0,159)$ & $(0,090)$ & $(0,048)$ & $(0,094)$ \\
\hline $\mathrm{N}$ & 1.940 & 1.940 & 1.940 & 1.940 \\
\hline
\end{tabular}

Em relação às variáveis de controle, identifica-se que apenas a variável governança corporativa (GC) pareceu não exercer influência sobre a rentabilidade das empresas, contrariado o que era esperado. A variável TAM apresentou significância a $1 \%$, tanto na estimação com dados agrupados quanto nas estimações para os três quantis, indicando um forte efeito do tamanho sobre a rentabilidade da empresa. A variável MTB apresentou significância estatística a $1 \%$ nas estimações com dados agrupados e quantílica para $01^{\circ}$ quantil e para o $5^{\circ}$ quantil, também indicando o Market to Book auxilia a explicar a rentabilidade da empresa. $O$ Indice de Liquidez Corrente apresentou relação negativa com o ROE embora não significante para as empresas de maior rentabilidade ( $9^{\circ}$ Quantil). A variável TANG apresentou significância apenas a $10 \%$, sugerindo um efeito baixo desta variável sobre a rentabilidade das empresas.

A relação positiva entre a variável TAM e a rentabilidade das empresas foi condizente com os resultados de Abor (2005) e no grupo de empresas manufatureiras de Gill, Biger e Mathur (2011). Tal relação é explicada pelos estudos de Nakamura et al (2007) e Brito, Corrar e Batistella (2007), pois, quanto maior a empresa, maior sua capacidade de resolver problemas de assimetria informacional, menores são seus custos na captação de recursos e mais diversificados são seus portfólios. Por outro lado, Gill, Biger e Mathur (2011) encontraram uma relação negativa entre essas variáveis quando analisaram a área de prestação de serviços.

O efeito negativo da variável ILC está em consonância com a Teoria do Pecking Order, enquanto o efeito da variável MTB, conforme Bastos, Nakamura e Basso (2009), pode ser positivo ou negativo e a relação esperada pela variável tangibilidade seria positiva, diferentemente do que foi encontrado no presente estudo. 


\subsection{Efeito do Endividamento de Longo Prazo sobre a Rentabilidade}

Para testar a influência entre o endividamento de longo prazo sobre a rentabilidade, foi construída a seguinte hipótese 2 , segundo a qual o endividamento de longo prazo influencia, negativamente, a rentabilidade das empresas listadas na B3.

$\mathrm{Na}$ tabela 06 , estão os resultados da segunda regressão. O maior valor do VIF para esta regressão foi igual a 1,21, atestando a ausência de multicolinearidade entre as variáveis.

Os resultados apresentados, na tabela 06 , se mostram inconclusivos para o efeito do endividamento de longo prazo sobre a rentabilidade, não corroborando os achados de Abor (2005) e (2007), que encontrou uma relação negativa, estatisticamente significante, entre estas variáveis. Também, estão em desacordo com Gill et al (2011), que identificaram uma relação positiva entre o endividamento de longo prazo e a rentabilidade das empresas. Portanto, não é possível rejeitar a hipótese 2.

\begin{tabular}{|c|c|c|c|c|}
\hline & pols & 10 Quantil & 5o Quantil & 9 Quantil \\
\hline & $\mathrm{b} / \mathrm{se}$ & b/se & b/se & b/se \\
\hline \multirow{2}{*}{ ELP } & 0,0004 & 0,0027 & $-0,0003$ & $-0,0045+$ \\
\hline & $(0,001)$ & $(0,002)$ & $(0,001)$ & $(0,002)$ \\
\hline \multirow{2}{*}{ TAM } & $0,0339^{* *}$ & $0,0312^{* *}$ & $0,0239^{* *}$ & $0,0111^{* *}$ \\
\hline & $(0,008)$ & $(0,004)$ & $(0,002)$ & $(0,004)$ \\
\hline \multirow{2}{*}{ TANG } & $-0,1030+$ & $-0,0225$ & $-0,0302^{*}$ & 0,0091 \\
\hline & $(0,054)$ & $(0,028)$ & $(0,015)$ & $(0,030)$ \\
\hline \multirow{2}{*}{ GC } & $-0,0174$ & 0,0091 & 0,0001 & 0,0153 \\
\hline & $(0,028)$ & $(0,015)$ & $(0,008)$ & $(0,015)$ \\
\hline \multirow{2}{*}{ MTB } & $0,0567^{* *}$ & $0,0658^{* *}$ & $0,0517^{* *}$ & $0,0172+$ \\
\hline & $(0,010)$ & $(0,008)$ & $(0,004)$ & $(0,009)$ \\
\hline \multirow{2}{*}{ ILC } & $-0,0029^{*}$ & $-0,0034^{*}$ & $-0,0048^{\star *}$ & $-0,0044^{* *}$ \\
\hline & $(0,001)$ & $(0,001)$ & $(0,001)$ & $(0,001)$ \\
\hline \multirow{2}{*}{ _cons } & $-0,5843^{\star *}$ & $-0,7409^{* *}$ & $-0,3916^{\star *}$ & 0,1186 \\
\hline & $(0,157)$ & $(0,086)$ & $(0,047)$ & $(0,092)$ \\
\hline $\mathrm{N}$ & 1.940 & 1.940 & 1.940 & 1.940 \\
\hline
\end{tabular}

As variáveis de controle, à exceção de GC, apresentaram significância estatística com resultados semelhantes ao da regressão anterior em relação ao nível de significância e no que diz respeito ao efeito positiva/negativo com a variável dependente ROE.

Os resultados da regressão para o endividamento a longo prazo apresentaram, de forma geral, pontos divergentes em relação à literatura. Abor (2005), Yazdanfar e Öhman (2015) e Habib, Khan e Wazir (2016) evidenciaram uma relação negativa entre a rentabilidade e o endividamento de longo prazo, enquanto Gill, Biger e Mathur (2011) evidenciaram uma relação positiva tanto para as empresas manufatureiras quanto para as prestadoras de serviço. Os achados da presente pesquisa estão, entretanto, de acordo com Ebaid (2009), que não identificou relação estatisticamente significante entre tais variáveis.

\subsection{Efeito do Endividamento Total sobre a Rentabilidade}

Para testar a influência entre o endividamento total sobre a rentabilidade, foi construída a seguinte hipóteseH3: O endividamento total influencia negativamente a rentabilidade das empresas listadas na B3.

Sobre as variáveis da terceira regressão, também foi realizado o teste de multicolinearidade e identificou-se a sua ausência, conforme o maior VIF igual a 1,22.

A partir dos dados da tabela 08, é possível afirmar que a hipótese 3 não pode ser refutada devido à ausência de significância estatística inferior a 5\%. Nesse sentido, faltam argumentos estatísticos e econômicos para afirmar ou negar a relação entre o endividamento total e a rentabilidade. Não há, portanto, consonância entre os achados do presente trabalho aqueles de Abor (2005), que identificou um efeito negativo do endividamento total sobre a rentabilidade das empresas. 


\begin{tabular}{|c|c|c|c|c|}
\hline & pols & $q 10$ & $q 50$ & $q 90$ \\
\hline & b/se & b/se & b/se & b/se \\
\hline \multirow[t]{2}{*}{ ET } & 0,0007 & 0,0027 & $-0,0005$ & $-0,0043+$ \\
\hline & $(0,001)$ & $(0,002)$ & $(0,001)$ & $(0,002)$ \\
\hline \multirow[t]{2}{*}{ TAM } & $0,0340^{* *}$ & $0,0314^{* *}$ & $0,0239^{* *}$ & $0,0119^{* *}$ \\
\hline & $(0,008)$ & $(0,004)$ & $(0,002)$ & $(0,004)$ \\
\hline \multirow[t]{2}{*}{ TANG } & $-0,1027+$ & $-0,0230$ & $-0,0302^{*}$ & 0,0140 \\
\hline & $(0,054)$ & $(0,028)$ & $(0,015)$ & $(0,030)$ \\
\hline \multirow[t]{2}{*}{$\mathrm{GC}$} & $-0,0174$ & 0,0087 & 0,0001 & 0,0187 \\
\hline & $(0,028)$ & $(0,014)$ & $(0,008)$ & $(0,015)$ \\
\hline \multirow[t]{2}{*}{ MTB } & $0,0567^{* *}$ & $0,0658^{* *}$ & $0,0516^{* *}$ & $0,0177^{*}$ \\
\hline & $(0,010)$ & $(0,008)$ & $(0,004)$ & $(0,009)$ \\
\hline \multirow[t]{2}{*}{ ILC } & $-0,0028^{*}$ & $-0,0034^{*}$ & $-0,0049 * *$ & $-0,0043^{* *}$ \\
\hline & $(0,001)$ & $(0,001)$ & $(0,001)$ & $(0,001)$ \\
\hline \multirow[t]{2}{*}{ _cons } & $-0,5878^{* *}$ & $-0,7437^{* *}$ & $-0,3915^{* *}$ & 0,0970 \\
\hline & $(0,158)$ & $(0,087)$ & $(0,047)$ & $(0,093)$ \\
\hline $\mathrm{N}$ & 1.940 & 1.940 & 1.940 & 1.940 \\
\hline
\end{tabular}

O modelo estimado encontrou significância estatística para quatro das cinco variáveis de controle, sendo GC a única a não apresentar alguma evidência de efeito sobre a rentabilidade das empresas, conforme identificados nas regressões anteriores. As variáveis TAM, MTB e ILC apresentaram p-valores inferiores a $5 \%$, tanto no modelo POLS quanto nas regressões quantílicas. A variável TANG não se mostrou estatisticamente significante para o primeiro quantil e o nono quantil da amostra, entretanto mostrou-se significante a $5 \%$ para a mediana (regressão quantifica) e na estimação POLS, que utiliza os desvios em relação à média.

Tais resultados estão contrários ao que tem mostrado a maior parte da literatura sobre o tema: Abor (2005), Yazdanfar e Öhman (2015) e Habib, Khan e Wazir (2016) identificaram a existência de relação negativa entre a rentabilidade e o endividamento total e Gill, Biger e Mathur (2011) encontraram uma relação positiva entre o endividamento total e a rentabilidade nas empresas manufatureiras e nas prestadoras de serviço. Divergentemente, os achados do presente trabalho estão em linha com Ebaid (2009), cujos resultados não apontaram uma correlação entre tais variáveis.

\section{CONSIDERAÇÕES FINAIS}

Este artigo teve como objetivo investigar as relações entre a estrutura de capital e a rentabilidade das empresas listadas na B3. Esse objetivo foi alcançado ao realizar testes através da regressão quantílica e com dados agrupados, em que três modelos foram estimados, cuja variável de teste representou o tipo de estrutura de capital, e diversas variáveis de controle aumentaram a robustez dos resultados.

Dessa forma, este estudo traz contribuições para a literatura relacionada à estrutura de capital e à rentabilidade ao demonstrar novas evidências dos efeitos que a estrutura de capital possui sobre a rentabilidade, além de variáveis como a governança corporativa e o tamanho das empresas. As contribuições também refletem no aspecto prático, pois as empresas poderão adotar a melhor estrutura de endividamento que Ihe ofereça maior rentabilidade. Os resultados geram, ainda, impactos sobre os gestores e suas organizações e para os pesquisadores da área de negócios nos seguintes sentidos: (i) auxiliam gerentes financeiros e gestores a conhecer as vantagens e dificuldades ensejadas por diferentes fontes de financiamento e os permite identificar opções para a melhoria da estrutura de capitais; (ii) contribuem para futuros estudos sobre a temática em tela, aumentando, assim, o acervo numa área pouco explorada em pesquisas nacionais.

Por meio dos resultados das regressões, foram obtidos pontos convergentes e divergentes em relação a estudos anteriores. Apenas o endividamento de curto prazo apresentou significância estatística a partir dos modelos utilizados e sugeriu um efeito positivo deste sobre a rentabilidade. Resultado alinhado às pesquisas que encontraram relação positiva entre a dívida de curto prazo e a rentabilidade das empresas de Mesquita e Lara (2004), Abor (2005) e Gill, Bigger e Mathur (2011). E a relação entre os coeficientes das variáveis ELP e ET, com a rentabilidade, não apresentou significância estatística. 
Tais resultados divergiram dos estudos de Abor (2005) e Gill et al (2011) e mostraram-se convergentes com Ebaid (2009), que não identificou relação estatisticamente significante entre tais endividamentos de longo prazo, o total e a rentabilidade.

Identificou-se que o financiamento de curto prazo afeta positivamente a rentabilidade, algo que contraria a teoria da irrelevância da fonte de financiamento proposta por Modigliani e Miller (1958) e sugere que, no contexto brasileiro, pode existir uma predileção por financiamento através de capital de terceiros, ao menos nas empresas com maior rentabilidade e com menor rentabilidade.

Não é possível afirmar que tais achados contrariam a proposição da teoria de Pecking Order proposta por Myers (1984), uma vez que muitas das empresas que compuseram a amostra podem ter obtido benefícios fiscais por captarem recursos por meio de financiamentos ou mesmo podem ter conseguido algum tipo de incentivo governamental. Tais especificidades ficaram fora do escopo desta pesquisa e ensejam novas pesquisas para uma melhor compreensão.

Os achados desta pesquisa, ainda que inconclusivos para os efeitos do endividamento de longo prazo e total, avançam em relação aos estudos anteriores sobre esta temática ao apontar que, para a amostra analisada, o efeito da estrutura de capital sobre a rentabilidade não é linear. Contribui, portanto, ao aplicar um método de estimação ainda pouco explorado na literatura em contabilidade e finanças e que se mostrou aderente às características dos dados.

Entre as vantagens da estimação quantílica, Girão (2016) aponta a possibilidade de aplicação do método semiparamétrico em dados com presença de heterocedasticidade, permeados por valores extremos (outliers) que não atendem ao pressuposto de normalidade dos resíduos. Isso é relevante pois as correções apresentadas para modelos paramétricos podem levar à perda de dados relevantes e não traduzir os dados examinados em sua complexidade.

Como limitações da pesquisa, é possível apontar o lapso temporal de apenas nove anos (2011 a 2019), além da não utilização de estimação com dados em painel em paralelo ao modelo com dados agrupados e mesmo a adoção do modelo não paramétrico Theil-Sen (TS), que tem se mostrado robusto a problemas de heterocedasticidade e outliers (OHLSON e KIM, 2015; DUARTE, GIRÃO e PAULO, 2017).

Recomenda-se que futuras pesquisas testem a relação entre estrutura de capital e rentabilidade com o acréscimo de outras variáveis de controle, se possível, com um período maior ou novos modelos econométricos, para observar se os resultados convergem para os achados encontrados por este e outros estudos.

\section{REFERÊNCIAS}

ABOR, J. The effect of capital structure on profitability: empirical analysis of listed firms in Ghana. Journal of Risk Finance, 6(5), pp. 438-445, 2005.

ABOR, J. Debt policy and performance of SMEs: Evidence from Ghanaian and South African firms. The Journal of Risk Finance, 8(4), 364-379, 2007.

AGUIAR, Andson Braga de; PIMENTEL, Renê Coppe. Remuneração de executivos e desempenho no mercado brasileiro: relações contemporâneas e defasadas. Revista de Administração Contemporânea, v. 21, n. 4, p. 545-568, 2017.

AHMAD, Ahmad Yahiya Ahmad Bani. The ability of accounting information systems to support profitability and growth (Industrial Sector-Jordan Companies). European Journal of Business and Management, v. 5, n. 19, p. 173-179, 2013.

ALBANEZ, Tatiana; VALLE, Maurício Ribeiro do. Impactos da assimetria de informação na estrutura de capital de empresas brasileiras abertas. Revista Contabilidade \& Finanças, v. 20, n. 51, p. 6-27, 2009.

BASTOS, D. D.; NAKAMURA, W. T. Determinantes da estrutura de capital das companhias abertas no Brasil, México e Chile no período 2001-2006. Revista Contabilidade \& Finanças, 20(50), 75-94, 2009.

BASTOS, D. D.; NAKAMURA, W. T.; BASSO, L. F. C. Determinantes da estrutura de capital das companhias abertas na América Latina: um estudo empírico considerando fatores macroeconômicos e institucionais. Revista de Administração Mackenzie, 10(6), 47-77, 2009.

BITTENCOURT, Wanderson Rocha; ALBUQUERQUE, Pedro Henrique Melo. Estrutura de capital: uma revisão bibliográfica das publicações dos periódicos nacionais. Revista Contemporânea de Contabilidade, v. 15, n. 34, p. 94114, 2018.

BREALEY, R. A.; MYERS, S. C.; ALLEN, F. Principles of Corporate Finance. 10thEdition, McGraw-Hill, 2011. BRITO, G. A. S.; CORRAR, L. J.:BATISTELLA, F. D. Fatores determinantes da estrutura de capital das maiores empresas que atuam no Brasil. Revista Contabilidade \&Finanças, 43(18), 9-19, 2007.

BRITO, Ricardo D.; LIMA, Mônica R. A escolha da estrutura de capital sob fraca garantia legal: o caso do Brasil. Revista Brasileira de Economia, v. 59, n. 2, p. 177-208, 2005.

CAMILO, S.P.; XAVIER, W. G, BANDEIRA-DE-MELLO, R.; MARCON, R. A estrutura de capital como recurso e o efeito no desempenho das firmas. Revista lbero Americana de Estratégia, 9(1), 2010. 
CARVALHO, G. A.; RIBEIRO, J. E.; AMARAL, H. F. Determinantes da Estrutura de Capital das Empresas que compõe o Índice Small Caps da B3. XVII USP International Conference in Accounting. São Paulo, 2018.

CATAPAN, Anderson; COLAUTO, Romualdo Douglas. Governança corporativa: uma análise de sua relação com o desempenho econômico-financeiro de empresas cotadas no Brasil nos anos de 2010-2012. Contaduría y Administración, v. 59, n. 3, p. 137-164, 2014.

CORREA, Carlos Alberto; BASSO, Leonardo Fernando Cruz; NAKAMURA, Wilson Toshiro. A estrutura de capital das maiores empresas brasileiras: análise empírica das teorias de pecking order e trade-off usando panel data. Revista de Administração Mackenzie (Mackenzie Management Review), v. 14, n. 4, 2013.

COSTA, Lilian; SAMPAIO, Joelson de Oliveira; FLORES, Eduardo Silva. Diversidade de Gênero nos Conselhos Administrativos e sua Relação com Desempenho e Risco Financeiro nas Empresas Familiares. Revista de Administração Contemporânea, v. 23, n. 6, p. 721-738, 2019.

DAVID, M.; NAKAMURA, W. T.; BASTOS, D. D. Estudo dos modelos trade-off e pecking order para as variáveis endividamento e payout com empresas brasileiras (2000-2006). Revista de Administração Mackenzie (RAM), 10(6), 132-153, 2009.

DIAS, Alexandre Teixeira et al. As influências da governança corporativa e da estrutura de capital no desempenho e no risco da firma. Revista Gestão \& Tecnologia, v. 20, n. 2, p. 98-120, 2020.

DUARTE, Filipe Coelho de Lima; GIRÃO, Luiz Felipe de Araújo Pontes; PAULO, Edilson. Avaliando Modelos Lineares de Value Relevance: Eles Captam o que Deveriam Captar? Revista de Administração Contemporânea, v. 21, n. spe p. 110-134, 2017.

EBAID, I. E. S. The impact of capital-structure choice on firm performance: empirical evidence from Egypt. The journal of risk Finance, 2009.

FAMA, E. F.; FRENCH, K. R. Testing trade-off and pecking order predictions about dividends and debt. The Review of Financial Studies, 15(1), 1-33, 2002.

FU, Tze-Wei; KE, Mei-Chiu; HUANG, Yen-Sheng. Capital growth, financing source and profitability of small businesses: evidence from Taiwan small enterprises. Small Business Economics, v. 18, n. 4, p. 257-267, 2002.

GILL, A.; BIGER, N.; MATHUR, N. The effect of Capital Structure on Profitability: Evidence form the United States. International Journal of Management, 2011.

GIRÃO, L. F. A. P.Competição por informações, ciclo de vida e custo do capital no Brasil (Tese). Universidade Federal da Paraíba, João Pessoa, 2016.

GORLA, M. C.; HEIN, N.; SILVA, J. C. Efeito Moderador de Fatores Macroambientais na Relação entre a Estrutura de Capital e o Desempenho Econômico de Empresas dos Países que compõem o G20. XVII USP International Conference in Accounting. São Paulo, 2018.

GOTARDELO, D. R. Estudo das práticas de governança corporativa e o desempenho organizacional: uma análise envolvendo rentabilidade, volatilidade e valor de mercado. (Doctoral dissertation), Dissertação de Mestrado em Administração, Faculdade de Administração da Pontifícia Universidade Católica de Minas Gerais (PUC-Minas), Belo Horizonte, MG, Brasil), 2006.

HABIB, H.; KHAN, F.; WAZIR, M. Impact of debt on profitability of firms: Evidence from non-financial sector of pakistan. City University Research Journal, 6(01), 2016.

HAUSSMAN, D. C. S.; VOGT, M.; HEIN, N.; HEIN, A. K., T. P. (2018). Relação entre Estrutura de Capital e Estrutura de Propriedade de Empresas Brasileiras: Trade-Off Decision Analysis. XVII USP International Conference in Accounting. São Paulo.

JENSEN, M. C.; MECKLING, W. H. Theory of the firm: Managerial behavior, agency costs and ownership structure. Journal of Financial Economics, 3(4), 305-360, 1976.

KIESCHNICK, Robert; MOUSSAWI, Rabih. Firm age, corporate governance, and capital structure choices. Journal of Corporate Finance, v. 48, p. 597-614, 2018.

KOENKER, R.; BASSETT JR, G. Regression quantiles. Econometrica, v. 46, n. 1, p. 33-50, 1978.

LEITE, Maurício; SILVA, Tarcísio Pedro da. Relação da estrutura de Capital e do valor econômico agregado no desempenho econômico em empresas industriais brasileiras e chilenas. Revista Facultad de Ciencias Económicas: Investigación y Reflexión, v. 27, n. 1, p. 11-42, 2019.

LERNER, A. F.; MEIRELLES, W.; VICTOR, F. G. Estrutura de Capital Como Determinante das Oportunidades de Crescimento: O Caso das Companhias Listadas na B3. XVII USP International Conference in Accounting. São Paulo, 2018.

MAIA, L. L.; CASTRO, M. C. C. S.; LAMOUNIER, W. M. Determinantes da Estrutura de Capital das Instituições Financeiras do Brasil.XVII USP International Conference in Accounting. São Paulo, 2018.

MARÇAL, Ronan R. et al. Relação entre os Investimentos em Atividades Exploratórias e a Descoberta de Novas Reservas de Petróleo: Um Estudo com as Empresas da NYSE. Revista Evidenciação Contábil \& Finanças, v. 7, n. 2. 2019.

MARTINS, Henrique Castro; TERRA, Paulo Renato Soares. Determinantes nacionais e setoriais da estrutura de capital 
na América Latina. Revista de Administração Contemporânea, v. 18, n. 5, p. 577-597, 2014.

MATIAS, F., SERRASQUEIRO, Z. Are there reliable determinant factors of capital structure decisions? Empirical study of SMEs in different regions of Portugal. Research in International Business and Finance, 40, 19-33, 2017.

MEDEIROS, Otávio Ribeiro de; DAHER, Cecílio Elias. Testando teorias alternativas sobre a estrutura de capital nas empresas brasileiras. Revista de Administração contemporânea, v. 12, n. 1, p. 177-199, 2008.

MESQUITA, J. M. C.; LARA, J. E. Capital Structure and Profitability: The Brazilian Case. Journal of Finance, v. 14, 2004.

MODIGLIANI, F.; MILLER, M. H. The cost of capital, corporation finance and the theory of investment. The American economic review, v. 48, n. 3, p. 261-297, 1958.

MODIGLIANI, Franco; MILLER, Merton H. Corporate income taxes and the cost of capital: a correction. The American economic review, p. 433-443, 1963.

MORANTE, Antonio Salvador; TIMACO, Jorge Fauzi. Administração financeira: decisões de curto prazo, decisões de longo prazo, indicadores de desempenho. São Paulo, Editora Atlas, 2009.

MYERS, S. C. The capital structure puzzle. The journal of finance, 39(3), 574-592, 1984.

MYERS, Stewart C.; MAJLUF, Nicholas S. Corporate financing and investment decisions when firms have information that investors do not have. National Bureau of Economic Research, 1984.

NAKAMURA, W. T.; MARTIN, D. M. L.; FORTE, D.; CARVALHO FILHO; A. F.; COSTA A. C. F.; AMARAL, A. C. Determinantes de estrutura de capital no mercado brasileiro: análise de regressão com painel de dados no período 1999-2003. Revista Contabilidade \& Finanças, 18(44), 72-85, 2007.

NASCIMENTO, João Carlos Hipólito Bernades do et al. As relações entre governança corporativa, risco e endividamento e suas influências no desempenho financeiro e no valor de mercado de empresas brasileiras. Advances in Scientific and Applied Accounting, v. 11, n. 1, p. 166-185, 2018.

OHLSON, J. A.; KIM, S. Linear valuation without OLS: the Theil-Sen estimation approach. Review of Accounting Studies, v. 20, n. 1, p. 395-435, 2015.

PAMPLONA, Edgar; DA SILVA, Tarcísio Pedro. Influência da estrutura de capital no desempenho de empresas brasileiras sob a ótica não linear. Estudios Gerenciales, v. 36, n. 157, p. 415-427, 2020.

PEROBELLI, Fernanda Finotti Cordeiro; FAMÁ, Rubens. Fatores determinantes da estrutura de capital para empresas latino-americanas. Revista de Administração Contemporânea, v. 7, n. 1, p. 9-35, 2003.

PINHO, C. R. C. Estrutura de Capitais e Lucratividade Empresarial: Evidências em Portugal. Dissertação. Universidade do Porto, 2013.

QUEIROZ, Juliana Molina et al. Governança Corporativa: Uma Análise das Empresas da Nova Economia. In: VIII Congresso Nacional de Administração e Contabilidade-AdCont 2017. 2017.

RAJAN, Raghuram G.; ZINGALES, Luigi. What do we know about capital structure? Some evidence from international data. The journal of Finance, v. 50, n. 5, p. 1421-1460, 1995.

SANTOS, K. P.; CAVICHIOLI, D.; ARAUJO, M. P.; DALL'ASTA, D. Estrutura de Capital das Empresas Brasileiras do Setor de Consumo Cíclico: uma Análise de Dados em Painel. XVII USP International Conference in Accounting, 2018.

SILVA, A. C.; STEINKE, A.; ZANCHET, A. Estrutura de Capital e Grau de Disclosure Voluntário: um Determinante do Custo de Capital de Terceiros. XVII USP International Conference in Accounting, 2018.

SILVA JÚNIOR, Claudio Pilar da; MARTINS, Orleans Silva. Mulheres no conselho afetam o desempenho financeiro? uma análise da representação feminina nas empresas listadas na BM\&FBOVESPA. Sociedade, Contabilidade e Gestão, v. 12, n. 1, 2017.

SIMERLY, R. L.; LI, M. Environmental dynamism, capital structure and performance: a theoretical integration and an empirical test. Strategic management journal, v. 21, n. 1, p. 31-49, 2000.

SOUZA, Daniel Henrique de Oliveira; PEIXOTO, Fernanda Maciel; SANTOS, Murilo Alves. Efeitos da governança corporativa na distribuição de dividendos: um estudo em empresas brasileiras. Advances in Scientific and Applied Accounting, v. 9, n. 1, p. 058-079, 2016.

WALD, J.K. How firm characteristics affect capital structure: An international comparison. Journal of Financial Research, 22(2), pp. 161-87, 1999.

YAZDANFAR, D., ÖHMAN, P. Debt financing and firm performance: an empirical study based on Swedish data. The Journal of Risk Finance, 16(1), 102-118, 2015. 